\title{
An update on the management of young-onset Parkinson's disease
}

This article was published in the following Dove Press journal:

Degenerative Neurological and Neuromuscular Disease

4 October 2013

Number of times this article has been viewed

\section{Nataša Klepac' \\ Mario Habek' \\ Ivan Adamec' \\ Anabella Karla Barušićl \\ Ivo Bach' \\ Eduard Margetić ${ }^{2}$ \\ Ivo Lušić ${ }^{3}$}

'Department of Neurology, Clinical University Hospital Zagreb, Medical

School, University of Zagreb, Zagreb, Croatia; ${ }^{2}$ Department of Cardiology, Clinical University Hospital Zagreb, Medical School, University of Zagreb, Zagreb, Croatia; ${ }^{3}$ Department of Neurology, Clinical University Hospital, Medical School, University of Split, Split, Croatia
Correspondence: Nataša Klepac Department of Neurology,

Clinical University Hospital Zagreb, Medical School, University of Zagreb, Kišpatićeva 12, Zagreb 10000, Croatia

Tel +3859854 I880

Fax +385 | 2388784

Email natasa.klepac@zg.t-com.hr

\begin{abstract}
In the text that follows, we review the main clinical features, genetic characteristics, and treatment options for Parkinson's disease (PD), considering the age at onset. The clinical variability between patients with PD points at the existence of subtypes of the disease. Identification of subtypes is important, since a focus on homogenous group may lead to tailored treatment strategies. One of the factors that determine variability of clinical features of PD is age of onset. Young-onset Parkinson's disease (YOPD) is defined as parkinsonism starting between the ages of 21 and 40. YOPD has a slower disease progression and a greater incidence and earlier appearance of levodopa-induced motor complications; namely, motor fluctuations and dyskinesias. Moreover, YOPD patients face a lifetime of a progressive disease with gradual worsening of quality of life and their expectations are different from those of their older counterparts. Knowing this, treatment plans and management of symptoms must be paid careful attention to in order to maintain an acceptable quality of life in YOPD patients.
\end{abstract}

Keywords: therapy, clinical features, dopamine agonist, levodopa, dyskinesia

\section{Introduction}

Young-onset Parkinson's disease (YOPD) is a subtype of Parkinson's disease (PD), occurring at a younger age, with specific symptoms, genetic correlation, and treatment strategies. YOPD is defined as the diagnosis of PD between the ages of 21 and $40 .{ }^{1} \mathrm{~A}$ positive PD diagnosis under the age of 21 is referred to as "juvenile Parkinson's" (JP). Between $3 \%$ and $6 \%$ of all PD cases are reported to be YOPD. ${ }^{1-3}$ Although most clinical features of JP and YOPD are the same, increased occurrence of dystonia and PD are found in families of patients with JP. ${ }^{4}$ The overall age and gender adjusted incidence of PD is 13.4 per 100,000 , whereas the incidences for people between the ages of 30 and 39,40 and 49 , and 50 and 59 are $0.5,2.5$, and 9.8 per 100,000, respectively. ${ }^{5}$ Approximately $20 \%$ of YOPD patients have at least one first- or second-degree relative with PD either in the same or antecedent generation. ${ }^{6}$ The aim of this review is to give an overview of specific clinical manifestations, genetic background, and potential environmental factors of YOPD with strong focus on current treatment options and strategies available for YOPD.

\section{Clinical manifestations}

Although the diagnosis of YOPD is based on clinical symptoms and family history of Parkinson's disease or any other movement disorders, there must be exclusion of secondary causes of parkinsonian symptoms. Some of these secondary causes include Wilson's disease, dopa-responsive dystonia, drug-induced parkinsonism, 
spinocerebellar ataxia, iron accumulation disorders, and structural abnormalities. To exclude these possible secondary causes, such as drug-induced parkinsonism, a detailed history of all neuroleptic and antiemetic drug use should be recorded. Measurement of serum and urinary copper, and screening for Kayser-Fleischer rings should be performed to exclude Wilson's disease.

\section{Motor symptoms}

The classical clinical appearance of PD consists of a resting tremor (3-6 Hz, usually unilateral on presentation), cogwheel rigidity, bradykinesia, and sometimes compromised postural reflexes and gait instability. ${ }^{7,8}$ Another sign, which is $100 \%$ sensitive but not completely specific for PD, may be a positive response to levodopa. ${ }^{7}$ The symptoms that appear in YOPD are similar to the classical symptoms of late-onset PD (LOPD), but some clinical features seem to be more prominent in YOPD.

In one study comparing clinical symptoms of YOPD versus LOPD it was concluded that YOPD patients more commonly present with increased muscle stiffness (43\%), while LOPD patients more often present with increased difficulty walking later on in the illness (33\%). ${ }^{9}$ Postural instability is more commonly seen in LOPD than in YOPD. ${ }^{1}$

It was shown that "wearing-off," "on-off" dystonia, and levodopa dyskinesia ${ }^{10}$ as well as dyskinesia in general ${ }^{11}$ were much more prominent in YOPD patients (59\% versus 37\%). ${ }^{12}$ Although, as previously mentioned, this very well could be a side effect of therapy. ${ }^{1,11,13,14}$ More specifically, it has been demonstrated that the most common type of dyskinesia is peak-dose dyskinesia, which includes stereotypic, choreic, or ballistic movements involving the head, trunk, limbs, and occasionally respiratory muscles. ${ }^{15-17}$ Another study confirming these findings showed that about one-third of YOPD patients had off-period dystonia, while LOPD patients were not observed to have dystonia during the study. ${ }^{9}$ The differences observed in the prevalence of tremor and bradykinesia between YOPD and LOPD were not statistically significant. ${ }^{10}$ YOPD patients were also shown to have increased motor fluctuations (69\%) in comparison to LOPD patients $(46 \%) .{ }^{12}$ In JP dystonia (60\% in JP versus $14 \%$ for YOPD) and akinetic rigidity (69\% in JP versus $20 \%$ for YOPD) are much more common. ${ }^{18}$

\section{Non-motor symptoms}

It has been demonstrated that after median disease duration of 18 years, the prevalence of cognitive impairments is only $19 \%$, of which $13 \%$ is under the age of $60 .{ }^{19}$ YOPD patients have a decreased incidence of cognitive degeneration when compared with LOPD. ${ }^{1,18-20}$ It has been postulated that there may be a difference in the types of Parkinson's between YOPD and LOPD with motor deterioration predominating the symptoms of YOPD and mental deterioration predominating the symptoms of LOPD. ${ }^{21}$

YOPD patients have been shown to have many psychological symptoms such as psychosis, confusion, and even hallucinations; these symptoms were present in only $13 \%$ of patients who had disease duration less than 10 years, and positively correlated with the duration of disease. ${ }^{18}$ Depression was also correlated with YOPD, this was postulated to possibly be a consequence of a longer duration of disease and decreased quality of life due to a high prevalence of motor symptoms. ${ }^{22}$ It was found that the mortality rate associated with YOPD is twice that of the normal population, but when compared with other PD patients it does not statistically vary. ${ }^{2,23,24}$

Paresthesias were also found to be in $20.5 \%$ of YOPD patients compared with $2 \%$ of the LOPD patients. ${ }^{11}$ Other non-motor symptoms, which were found to be more common in YOPD patients in comparison with LOPD patients, were restless legs and sweating. ${ }^{12}$ The presence of symptoms in YOPD and LOPD is shown in Table 1.

\section{Diagnosis}

The diagnosis of YOPD is still widely based on the judgment of clinical symptoms. The recently US Food and Drug Administration (FDA)-approved DaTSCAN is being questioned for its accuracy and overall contribution to the diagnosis of PD. It has been shown that the overall accuracy of clinical diagnosis is $84 \%$ in early $\mathrm{PD}$ and $98 \%$ at later stages of PD. The diagnosis of PD clinically is mathematically just as accurate as the diagnostic accuracy of DaTSCAN imaging. ${ }^{25}$ It must be kept in mind that the purpose of a

Table I Occurrence of symptoms in young- and late-onset Parkinson's disease

\begin{tabular}{ll}
\hline $\begin{array}{l}\text { Young-onset Parkinson's } \\
\text { disease }\end{array}$ & $\begin{array}{l}\text { Late-onset Parkinson's } \\
\text { disease }\end{array}$ \\
\hline - Motor fluctuations & - Postural instability \\
- "Off-time" dystonia & - Difficulty walking \\
- Muscle stiffness & - Cognitive degeneration \\
- Dyskinesia & \\
- Psychosis, confusion, hallucinations & \\
- Depression & \\
- Paresthesias & \\
- Restless legs & \\
- Sweating & \\
\hline
\end{tabular}


DaTSCAN is to aid in the diagnosis of PD and not to be a replacement of the clinical diagnosis.

It has also been shown that transcranial ultrasound can show hyperechogenicity in the substantia nigra of a PD patient. ${ }^{26-28}$ It has been postulated that this is due to the increased concentration of iron in some patients with PD. ${ }^{26-29}$ Furthermore, lower serum ceruloplasmin levels have been correlated with a younger onset of PD. ${ }^{26}$

\section{Genetic background and potential environmental factors in YOPD}

The genetic contribution to the etiology of YOPD is probably greater than in PD with later onset. ${ }^{30}$ Out of several genes, assumed to be associated with YOPD, five stand out and are mentioned more frequently in current literature than others (Table 2). ${ }^{31}$ Mutations in the PARK2 gene are the most common cause of autosomal recessive YOPD ${ }^{31-34}$ with an onset before age $40 .{ }^{35}$ PARK2 is an E3-type ubiquitin protein ligase involved in the proteosomal degradation of target proteins, including $\alpha$-synuclein. ${ }^{36}$ The accumulation of this protein results in neuronal death in substantia nigra and locus ceruleus. ${ }^{36}$ The second most common cause of autosomal recessive YOPD is PINK1 gene mutation. The discovery of PINK1 involvement in PD was the first evidence that a kinase signaling pathway could be important in the pathogenesis of dopaminergic nigral cell death. ${ }^{37}$ Moreover, it provided a link between mitochondrial dysfunction and neurodegeneration seen in PD. ${ }^{38,39}$ Another gene thought to be associated with YOPD is $P A R K 7$, involved in protection from oxidative stress

Table 2 Genes found to be significant in young-onset Parkinson's disease etiology and their mode of inheritance

\begin{tabular}{|c|c|c|}
\hline \multicolumn{3}{|l|}{ Mode of inheritance } \\
\hline Autosomal recessive & Gene product & Function \\
\hline $\begin{array}{l}\text { PARK2 } \\
(\text { OMIM*602544) }\end{array}$ & Parkin & $\begin{array}{l}\text { Plays a role in the cell } \\
\text { machinery that degrades } \\
\text { unneeded proteins }\end{array}$ \\
\hline $\begin{array}{l}\text { PINKI } \\
(\text { OMIM*608309) }\end{array}$ & $\begin{array}{l}\text { PTEN induced } \\
\text { putative kinase I }\end{array}$ & $\begin{array}{l}\text { Helps protect mitochondria } \\
\text { from malfunctioning during } \\
\text { period of cellular stress }\end{array}$ \\
\hline $\begin{array}{l}\text { PARK } 7 \\
(\text { OMIM*602533) }\end{array}$ & DJ-I protein & $\begin{array}{l}\text { Helps protect cells from } \\
\text { oxidative stress }\end{array}$ \\
\hline \multicolumn{3}{|l|}{ Autosomal dominant } \\
\hline $\begin{array}{l}\text { LRRK2 } \\
(\mathrm{OMIM} * 609007)\end{array}$ & Dardarin & $\begin{array}{l}\text { Plays a role in activities that } \\
\text { require interactions with } \\
\text { other proteins, such as } \\
\text { transmitting signals }\end{array}$ \\
\hline $\begin{array}{l}\text { SNCA } \\
(\text { OMIM*I63890) }\end{array}$ & $\alpha$-synuclein & $\begin{array}{l}\text { Plays a role in maintaining a } \\
\text { supply of synaptic vesicles } \\
\text { in presynaptic terminals }\end{array}$ \\
\hline
\end{tabular}

and chaperoning proteins such as $\alpha$-synuclein. ${ }^{36} \mathrm{PD}$ associated with LRRK2 mutations presents an onset distribution very similar to that seen in idiopathic $\mathrm{PD}$, as well as clear age-dependent penetrance. ${ }^{40-42}$ In 2009, Tong et al demonstrated that LRRK2 mutation affects activity-dependent dopamine (DA) neurotransmission and catecholamine release. ${ }^{43}$ Lastly, mutations in SNCA, although rare, cause $\mathrm{PD}$ to occur at a younger age than that seen for idiopathic PD. ${ }^{44}$ Given the correlation described recently between LRRK2 and $\mathrm{SNCA}^{45,46}$ and the impact of $\alpha$-synuclein overexpression on synaptic vesicle recycling, ${ }^{47}$ the regulation of neurotransmitter release might arise as one of the main biological pathways compromised during neuropathology onset. ${ }^{48}$ Additionally, a study conducted by Nichols et al suggests that patients carrying a glucocerebrosidase (GBA) variant exhibited PD symptoms 6.04 years earlier than those without a GBA variant. ${ }^{49}$ It is also important to note that the abovementioned LRRK2, SCNA, and GBA gene mutations increase the risk of sporadic PD, whereas many others are linked to familial forms of PD.

Apart from genes, environmental factors may also play a role in YOPD etiology. A study from Sao Paulo by Aguiar at al observed higher exposure to well-water drinking in the YOPD patient group. Most of the patients were exposed during first or second decades of life, for an average period of 14.3 years. ${ }^{34}$ Other potential environmental risk factors included pesticides, herbicides, and organic solvents. An inverse association between smoking and PD risk was not observed, suggesting a putative protective effect smoking might have on PD development. However, the authors argued that in the case of YOPD, the protective effects of smoking were not enough to overcome all other factors leading to neurodegeneration.

\section{Current treatment options and strategies available for YOPD Pharmacological treatment}

Which drugs to use when initiating pharmacotherapy in YOPD is a complex treatment decision that depends on factors such as disease severity, functional disability, and psychosocial handicap, as well as individual aspects of comorbidity and age. To date, the most effective treatment for PD has been shown to be levodopa. It is effective in treating symptoms such as bradykinesia and rigidity. The effects of levodopa on postural stability, speech, and gait disturbance is less pronounced.

Initially, YOPD patients have a good response to levodopa therapy, but as treatment progresses, motor symptoms resistant to levodopa develop. ${ }^{6,13,21}$ It seems that YOPD patients 
have a slower progression of disease but higher treatment complications with levodopa. ${ }^{1,11,13,14}$ In YOPD, treatment with levodopa is associated with early and prominent occurrence of motor complication, namely dyskinesia. In one study, it was observed that within the first week of treatment with levodopa, $25 \%$ of patients developed a complication; after 5 years of levodopa treatment, $91 \%$ of patients developed dyskinesias, and 92\% developed motor fluctuations; and after 12 years, all patients had those side effects. ${ }^{21} \mathrm{~A}$ similar trend was demonstrated by a study done in 1987 , where $100 \%$ of patients developed dyskinesias by the sixth year after therapy. ${ }^{6}$ Therefore, the treatment with levodopa should be postponed in this group of patients, although every PD patient progresses to the point where levodopa is necessary. ${ }^{50}$

Alternative treatment options to start therapy in YOPD are dopamine agonists, inhibitors of monoamine oxidase B (selegiline hydrochloride, or rasagiline mesilate), amantadine hydrochloride, or where tremor is a particular problem, anticholinergics - although use of the latter might be restricted by cognitive side-effects. ${ }^{51,52}$ All of these drugs can be used alone or in combination with levodopa to successfully treat PD. The decisions as to when to start drug treatment and which drugs to use in patients with YOPD depend on several factors, including disease severity, functional disability, comorbidity, personal expectations, employment status, and psychosocial handicap. ${ }^{50}$

Evidence suggests that the use of dopamine agonists rather than levodopa is associated with a decreased risk of developing motor complications. ${ }^{53-57}$ Long-term follow-up trials have confirmed that there are fewer dyskinesias and motor fluctuations in patients treated with dopamine agonists, but a decrease in moderate to severe dyskinesias was not noted to be very significant. ${ }^{58-60}$ This delay of dyskinesias and motor complications may be most appreciated in patients with YOPD. ${ }^{61}$ There is also some evidence that dopamine agonists may have a neuroprotective effect. ${ }^{62}$ This has been supported by functional imaging studies which demonstrate a decreased rate of decline of presynaptic dopaminergic functions. ${ }^{63,64}$ However, this conclusion comes from correlating the changes in imaging techniques rather than the clinical picture. Nonetheless, this information has led us to believe that starting therapy with dopamine agonists rather than levodopa could be beneficial. However, one must keep in mind that dopamine agonists also have many side effects. In PD patients treated with dopamine agonists, impulse control disorders including gambling, shopping, binge eating, and hypersexuality are observed. Other observed side effects of dopamine agonists are increased daytime sleepiness, leg edemas, and early hallucinations. ${ }^{65-67}$ However, the method of treatment which has been most supported for YOPD is initiation of treatment with dopamine agonists, increasing the dose until a balanced level of effectiveness and the level of maximum tolerance is reached. Levodopa is then added as adjuvant therapy as needed. ${ }^{68,69}$ This method of therapy seems most suitable in YOPD for avoiding early motor symptoms due to levodopa treatment.

Monoamine oxidase (MAO)-B inhibitors are effective in monotherapy and as an adjunct to levodopa therapy, with beneficial effects on quality of life parameters in early and late stages of PD. Studies have shown that MAO-B inhibitors reduce the incidence of motor fluctuations, decrease the need for levodopa, and reducing overall disability, with negligible side effects. The MAO-B inhibitors, used as monotherapy, delay the need for the introduction of levodopa by about 9 months. These agents appear to be less efficacious than dopamine agonists but are better tolerated. ${ }^{70}$

Amantadine could be used as a monotherapy or in combination with levodopa. There is some evidence that amantadin is useful in controlling dyskinesias, but evidence of its effectiveness in treating motor complications has not been convincing. ${ }^{71,72}$ Amantadine has been shown to reduce dyskinesia by $45 \%$ in patients with PD when it was compared with a placebo, but the positive effects were only sustained for 8 months, and when the patient experienced withdrawal from amantadine, there was an up to $20 \%$ increase in dyskinesias. ${ }^{73}$ Therefore, amantadine is usually used as add-on therapy when dyskinesias develop.

Anticholinergics are nowadays rarely used due to side effects such as cognitive disturbances. Sometimes one may consider using anticholinergics for treatment of severe tremor in YOPD. The therapeutic approach differs in late and early phase of PD. In the late stage of PD in YOPD, motor complications such as wearing-off, unpredictable offs, and dyskinesias predominate. Therefore addition and manipulation of doses of levodopa, dopamine agonists, MAO-B inhibitors, and inhibitors of catechol-O-methyltranferase (COMT) can all be helpful in improving these complications. COMT inhibitors in combination with levodopa enhance efficacy of levodopa on motor symptoms of PD due to prolongation of its effect.

Despite all the therapeutic possibilities for treating YOPD, one must bear in mind that YOPD patients face a lifetime of a progressive disease and many years of therapy. When manipulations of oral antiparkinsonian drugs are exhausted, patients with YOPD may be good candidates for continuous apomorphine infusions, surgery, or continuous 
levodopa treatment. For years it was believed that levodopa may have been toxic to dopaminergic neurons. ${ }^{74,75}$ Performance of levodopa infusions is a rather complex and expensive technique, which was a reason for restricting levodopa therapy for many years. Now opinions are changing, and it is believed that the decreased response to levodopa in late Parkinson's is due to progression of disease rather than toxic effects. ${ }^{76}$ Moreover, it is thought that continued delivery of levodopa to the brain help to prevent and improve motor complications. Physiological continuous stimulation of the dopaminergic neurons has been explored through duodenal, intrajejunal, or subcutaneous infusions. It has been shown that continuous stimulations improve motor symptoms. ${ }^{77}$

\section{Surgery}

\section{Deep brain stimulation (DBS)}

DBS is an FDA-approved surgical technique whereby electrical current is applied to various parts of the brain via implanted electrodes. ${ }^{78}$ In contrast to ablative procedures, it proves to be a safer method in the treatment of movement disorders, producing adverse effects that are generally reversible once the stimulation is terminated. ${ }^{79}$ The underlying mechanisms of DBS are not completely understood, although growing evidence supports the efficacy of DBS for the treatment of movement disorders including PD. ${ }^{79}$

Over the years, many targets have been used for the treatment of PD, including ventral intermediate nucleus (VIM), subthalmic nucleus (STN), and globus pallidus interna (GPi). ${ }^{79}$ Benabid et al found that in a series of $80 \mathrm{PD}$ patients treated with either unilateral or bilateral VIM DBS, $88 \%$ had complete or near-complete tremor relief on the Fahn-TolosaMarin Tremor Rating Scale at 6 months to 8 years postoperatively. ${ }^{80}$ The effects of VIM DBS on other symptoms of PD such as rigidity, bradykinesia, or drug-induced dyskinesia were either short lasting or nonexistent. ${ }^{80}$ STN DBS does not improve on-medication state UPDRS motor subscores but does lead to $52 \%$ improvement in the off-medication state UPDRS scores over a period of 15 months postoperatively. ${ }^{81}$ A $50 \%-60 \%$ reduction in postoperative levodopa dose leads indirectly to improvement in levodopa-induced dyskinesia. ${ }^{81,82}$ On-medication dyskinesias are reduced by 94\% after 12 months of STN DBS. ${ }^{82}$ Quality of life is significantly improved after STN DBS compared with medical therapy. ${ }^{78,83}$ However, recent data suggest that, although STN DBS improves motor components in both young and old patients, it is less effective in patients older than $65 .{ }^{84}$ Nevertheless, a recent study by Odekerken et al suggests that STN could be the preferred target for DBS in patients with advanced PD. ${ }^{85}$ DBS-associated problems in cognitive, mood, and behavioral features seem to occur more often in the STN stimulation. ${ }^{85-89}$ In PD patients, GPi DBS improves tremor, rigidity, and bradykinesia in off-medication state as well as drug-induced bradykinesia, resulting in overall improvement in UPDRS motor scores. ${ }^{90-92}$ The most pronounced and long-lasting effect is the reduction in on-medication dyskinesia. ${ }^{93}$ GPi DBS does not lead to reduction in the patient's levodopa requirement and might even increase after chronic GPi DBS therapy. ${ }^{94}$ YOPD patients are usually characterized by a slower disease progression, lower incidence of non-levodopa responsive symptoms, and more severe motor complications, ${ }^{18,95-97}$ thus representing ideal candidates for the DBS surgical option. ${ }^{98}$ A study by Merola et al showed that STN DBS-treated YOPD patients were associated with a medium- to long-term lower incidence of stimulation and medication resistant symptoms. ${ }^{98}$

\section{Ablation}

Currently, the options for ablation therapy include pallidotomy or thalamotomy, where the target structure may either be the globus pallidus or the thalamus. Palidotomy has been shown to reduce drug-induced dyskinesias and dystonias in PD patients who have previously had a successful response to pharmacological therapy. ${ }^{99}$ A unilateral pallidotomy usually improves symptoms on the contralateral side. ${ }^{100}$ There is a dispute whether a bilateral pallidotomy is a completely safe procedure. ${ }^{101}$

As with the pallidotomy a unilateral thalamotomy will be effective against symptoms on the contralateral side. It may improve tremor, rigidity, and dyskinesias but may worsen other parkinsonian symptoms such as bradykinesia, gait problems, postural instability, or speech disorders. ${ }^{74,102}$

Currently there is a new noninvasive method which is emerging and has been approved by the FDA to enroll 30 patients in its study for ablation by transcranial magnetic resonance (MR) imaging-guided focused ultrasound. ${ }^{102}$ It uses focused ultrasound waves, which converge at a specific point determined and guided by MR to ablate the malfunctioning structure in the brain (nucleus ventralis intermidius of the thalamus). The procedure includes real-time continuous MR imaging and MR thermometry monitoring, creating a very precise, safe, and effective way to treat patients. ${ }^{100,102-104}$

\section{Novel therapies}

Emerging therapeutic options for treating idiopathic PD, such as neurotrophic factors, cell-based therapy, neurotransmitter targets, and potentially neuroprotective drugs, are 
generating much interest but also controversy. ${ }^{105-108}$ Most recent treatment options for PD involve immunotherapy through vaccination and gene therapy. However, most of these treatment options focus very little on the YOPD subgroup of patients. Further research is needed to test their efficacy on YOPD patients specifically. These therapies are currently in experimental stages of development and have not been FDA approved.

\section{Cell-based therapy}

Cell-based therapy for PD has shown significant progress in recent years. ${ }^{104} \mathrm{~A}$ major advancement came with the use of fetal ventral mesencephalic (VM) tissue as a cell source for transplantation. Fetal dopamine (DA) neurons transplanted into the striatum of PD patients have survived, integrated, and provided motor benefits. ${ }^{109-111}$ The first neural transplantation used dissociated fetal VM tissue, which was transplanted into the striatum of young PD patients. Marked motor improvement and increased fluorodopa uptake in the striatum on positron emission tomography (PET) was observed. ${ }^{109}$ Indirect evidence of graft survival, obtained from PET studies, indicated that the transplanted fetal VM tissue can survive up to a decade and provide sustained motor benefits in PD. ${ }^{112}$ Additionally, it was shown that DA neuronal suspension grafts can survive, integrate, and display mature VM phenotypes providing functional benefits in the degenerating brain for years without side effects such as dyskinesia. ${ }^{113}$ In a trial with solid pieces of fetal VM tissue, clinical improvement was, to some degree, observed in YOPD but not in non-YOPD patients. ${ }^{11}$

\section{Immunotherapy}

$\mathrm{PD}$, as the second most common neurodegenerative entity, is of particular interest with regard to applying immunotherapy in clinical practice ${ }^{88}$ The major component of Lewy bodies, and neuropathological hallmark of PD, is $\alpha$-synuclein. ${ }^{88}$ The first experimental indication that $\alpha$-synuclein might be the causative agent in PD came from the analysis of rare autosomal dominant forms of PD in several families carrying three different point mutations in the SNCA gene leading to the formation of misfolded protein. ${ }^{88}$ Masliah et al investigated mice overexpressing human SNCA and either administrated a full-length $\alpha$-synuclein-based vaccine employing CFA/IFA (Freund's complete/incomplete adjuvant) as adjuvant ${ }^{89}$ or systemically administrated an $\alpha$-synucleinspecific monoclonal antibody. ${ }^{114}$ Both therapies were associated with reduced neurodegeneration and improved function. Recently, AFFITOPE ${ }^{\circledR}$ PD01 vaccine has been developed to induce antibodies recognizing $\alpha$-synuclein. ${ }^{88}$ Preclinical studies involving the subcutaneous administration of the vaccine demonstrated reactivity towards $\alpha$-synuclein with an additional functional benefit. ${ }^{88}$ Compared with controls, PD01-treated animals showed superior cognitive functions as assessed by the Morris water maze test. ${ }^{88}$

\section{Gene therapy}

In-vivo gene therapy is a new approach. ${ }^{115}$ Gene transfer of glutamic acid decarboxylase (GAD), rate-limiting enzyme in gamma-aminobutyric acid (GABA) production, and other methods that modulate the production of GABA in the subthalmic nucleus, improve basal ganglia function in parkinsonism in animal models. ${ }^{115}$ LeWitt et al assessed the effect of bilateral delivery of adeno-associated viral vector (AAV2)-GAD in the subthalmic nucleus compared with sham surgery in patients with advanced PD. The AVV2-GAD group showed significant improvement from baseline in unified PD rating scale (UPDRS) scores compared with sham group over the course of 6 months. ${ }^{115}$ A similar study involving neurturin, a naturally occurring analogue of glial cell-linederived neurotrophic factor, was conducted by Marks et al ${ }^{116}$ by bilateral delivery of AAV2-neurturin into the putamen. However, it showed no motor score improvement using the UPDRS in treated patients after 12 months. ${ }^{116}$

The selection of the best candidate for surgery among PD patients is a debated topic. YOPD patients could be the best candidates for this kind of treatment, because they have a slower disease progression and more competent compensatory mechanisms, and this could be beneficial for effects of transplantations. ${ }^{117}$

\section{Adjuvant therapies}

Physical and occupational therapy in YOPD patients should be used with pharmacological treatment and may assist in the rehabilitation process. Initiating an exercise program from the earliest stages of PD might benefit secondary motor problems involving arm swing, gait, and posture. ${ }^{118,119}$ Exercise has been shown to improve physical function, health-related quality of life, leg strength, balance, and gait speed in PD, and is possibly mediated through increased calcium/CaM-dependent dopamine synthesis in the remaining dopaminergic nigrostriatal cells. ${ }^{120,121}$ Service (trained) dogs are reported to help people with PD by interruption of rest tremor on stroking the dog and diminishing propulsive gait, ${ }^{118}$ perhaps by providing visual cues. ${ }^{122}$ YOPD patients with speech difficulties might benefit from intensive voice therapy to maintain employment and social activity. ${ }^{115}$ 


\section{Conclusion}

Many clinicians view age at onset as an important determinant of clinical phenotype in PD. YOPD is very similar to LOPD in many ways but requires special attention because it is different enough to require a different treatment approach. The available evidence suggests that PD patients with younger age at onset have slower disease progression, an increased rate of dystonia at onset, a lower rate of dementia, and an increased rate of dyskinesias in response to levodopa treatment. Which drugs to use when initiating pharmacotherapy in YOPD is a complex treatment decision that depends on factors such as disease severity, functional disability, and psychosocial handicap, as well as individual aspects of comorbidity and age. Without clear proof of a drug's capacity to markedly alter or even stop the progression of the disease, there is no strategy that can be viewed as universal treatment. Dopamine replacement strategies offer greatest symptomatic relief and are needed whenever there is significant functional disability. Physicians are slowly gravitating towards the notion that levodopa treatment does not have toxic effects on dopaminergic neurons; however, preventing dyskinesias and motor symptoms which begin shortly after levodopa treatment initiation in YOPD patients remains to be demonstrated. The therapeutic strategy for YOPD patients should include a relatively low threshold for initiation of treatment. The treatment should be initiated with a dopamine receptor agonist, with the dosage individually adjusted. In the cases where the treatment response is suboptimal, or if problematic adverse effects develop, levodopa should be added to the therapy. YOPD patients are also ideal candidates for DBS therapy with medium- to long-term lower incidence of stimulation and medication resistant symptoms. Regular physical exercise and physical therapy must be encouraged. Emerging therapeutic options for the treatment of YOPD, such as cell-based therapy are generating much interest from the scientific community, although their effectiveness remains to be established. Future therapeutic strategies should focus not only on ameliorating the symptoms of PD, but also on neuroprotective or neurorescue therapies that can favorably modify the natural course of the disease and slow the progression of manifestations of PD. YOPD patients are not only bearing the burden of motor complications but psychological problems, often overlooked, and a general decrease in the quality of life. Many studies have shown that proper treatment can significantly increase the quality of life in YOPD patients. For this reason, a custom tailored treatment plan is of interest, based on stage of the disease, degree of interference of the symptoms with social and occupational functioning, and response to treatment. The medical management of YOPD is complicated, and a multidisciplinary approach to care is vital to meet the psychological, emotional, and social needs of PD patients and their families.

\section{Key points}

- Diagnosis of PD before the age of 40 is considered YOPD.

- When suspecting YOPD, secondary causes of parkinsonian symptoms should be excluded (Wilson's disease, dopa-responsive dystonia, drug-induced parkinsonism, and structural abnormalities).

- After 6 years of levodopa therapy, almost all YOPD patients develop dyskinesias.

- Starting therapy with dopamine agonists delays the onset of levodopa-related motor symptoms until therapy with levodopa is initiated.

- DBS and ablation are available surgical options in the treatment of YOPD.

- Cell-based therapy, immunotherapy, and gene therapy are emerging therapeutic options in YOPD treatment.

- Physical and occupational therapy in YOPD patients should be used as an adjuvant therapy and may assist in the rehabilitation process.

\section{Disclosure}

The authors report no conflicts of interest in this work.

\section{References}

1. Golbe LI. Young-onset Parkinson's disease: a clinical review. Neurology. 1991;41(2):168-173.

2. Martilla RJ, Rine UK. Epidemiology of Parkinson's disease in Finland. Acta Neurol Scand. 1976;53(2):81-102.

3. Schrag A, Ben Shlomo Y, Quinn NP. Cross sectional prevalence survey of idiopathic Parkinson's disease and Parkinsonism in London. BMJ 2000;321(7252):21-22.

4. Muthane UB, Swamy HS, Satishchandra P, Subhash MN, Rao S, Subbakrishna D. Early onset Parkinson's disease: are juvenile- and young-onset different? Mov Disord. 1994;9(5):539-544.

5. Stephen K, Van Den Eeden C, Tanner M, et al. Incidence of Parkinson's Disease: variation by age, gender, and race/ethnicity. Am J Epidemiol. 2003;157(11):1015-1022.

6. Quinn N, Critchley P, Marsden CD. Young onset Parkinson's disease. Mov Disord. 1987;2(2):73-91.

7. Gelb DJ, Oliver E, Gilman S. Diagnostic Criteria for Parkinson Disease. Arch Neurol. 1999;56(1):33-39.

8. Calne DB, Snow BJ, Lee C. Criteria for diagnosing Parkinson's Disease. Ann Neurol. 1992;32(Suppl):125-127.

9. Gibb WRG, Lees AJ. A comparison of clinical and pathological features of young- and old-onset Parkinson's disease. Neurology. 1988;38(9): 1402-1406.

10. Jankovic J. Motor fluctuations and dyskinesias in Parkinson's disease: clinical manifestations. Mov Disord. 2005;20 (11):11-16.

11. Friedman A. Old-onset Parkinson's disease compared with youngonset disease: clinical differences and similarities. Acta Neurol Scand. 1994;89(4):258-261. 
12. Spica V, Pekmezović T, Svetel M, Kostić VS. Prevalence of non-motor symptoms in young-onset versus late-onset Parkinson's disease. J Neurol. 2013;260(1):131-137.

13. Pantelatos A, Fornadi F. Clinical features and medical treatment of Parkinson's disease in patient groups selected in accordance with age at onset. Adv Neurol. 1993;60:690-697.

14. Ku S, Glass GA. Age of Parkinson's disease onset as a predictor for the development of dyskinesia. Mov Disord. 2010;25(9):1177-1182.

15. Rascol O. Levodopa-induced peak-dose dyskinesias in patients with Parkinson's disease: a clinical pharmacologic approach. Mov Disord. 1999;14(1):19-32.

16. Jankovic J, Nour F. Respiratory dyskinesia in Parkinson's disease. Neurology. 1986;36(2):303-304.

17. Rice JE, Antic R, Thompson PD. Disordered respiration as a levodopa-induced dyskinesia in Parkinson's disease. Mov Disord. 2002;17(3):524-527.

18. Schrag A, Ben-Shlomo Y, Brown R, Marsden CD, Quinn N. Youngonset Parkinson's disease revisited - clinical features, natural history, and mortality. Mov Disord. 1998;13(6):885-894.

19. Goetz CG, Tanner CM, Stebbins GT, Buchman AS. Risk factors for progression in Parkinson's disease. Neurology. 1988;38(12): 1841-1844.

20. Hietanen $M$, Teravainen $H$. The effect of aging and onset on neuropsychological performance in Parkinson's disease. J Neurol Neurosurg Psychiatry. 1988;5(1):244-249.

21. Lieberman A, Dziatolowski M, Kupersmith M, et al. Dementia in Parkinson's disease. Ann Neurol. 1979;6:355-359.

22. Knipe MD, Wickremaratchi MM, Wyatt-Haines E, Morris HR, Ben-Shlomo Y. Quality of life in young- compared with late-onset Parkinson's disease. Mov Disord. 2011;26(11):2011-2018.

23. Ben-Shlomo Y, Marmot MG. Survival and cause of death in a cohort of patients with parkinsonism: possible clues to aetiology? J Neurol Neurosurg Psychiatry. 1995;58(3):293-299.

24. Bennett DA, Beckett LA, Murray AM, et al. Prevalence of parkinsonian signs and associated mortality in a community population of older people. N Engl J Med. 1996;334(2):71-76.

25. De la Fuente-Fernández R. Role of DaTSCAN and clinical diagnosis in Parkinson disease. Neurology. 2012;78(10):696-701.

26. Bharucha KJ, Friedman JK, Vincent AS, Ross ED. Lower serum ceruloplasmin levels correlate with younger age of onset in Parkinson's disease. J Neurol. 2008;255(12):1957-1962.

27. Hochstrasser H, Bauer P, Walter U, et al. Ceruloplasmin gene variations and substantia nigra hyperechogenicity in Parkinson disease. Neurology. 2004;63:1912-1917.

28. Berg D, Hochstrasser H, Schweitzer KJ, Riess O. Disturbance of iron metabolism in Parkinson's disease - ultrasonography as a biomarker. Neurotox Res. 2006;9(1):1-13.

29. Gotz ME, Double K, Gerlach M, Youdim MB, Riederer P. The relevance of iron in the pathogenesis of Parkinson's disease. Ann N Y Acad Sci. 2004;1012:193-208.

30. Rissling I, Strauch K, Höft C, Oertel WH, Möller JC. Haplotype analysis of the engrailed-2 gene in young-onset Parkinson's disease. Neurodegenerative Dis. 2009;6(3):102-105.

31. Macedo MG, Verbaan D, Fang Y, et al. Genotypic and phenotypic characteristics of Dutch patients with early onset Parkinson's disease. Mov Disord. 2009;24(2):196-203.

32. Choi JM, Woo MS, Ma HI, et al. Analysis of PARK genes in a Korean cohort of early-onset Parkinson disease. Neurogenetics. 2008;9(4): 263-269.

33. Guo JF, Zhang XW, Nie LL, et al. Mutation analysis of Parkin, PINK1 and DJ-1 genes in Chinese patients with sporadic early onset parkinsonism. J Neurol. 2010;257(7):1170-1175.

34. Aguiar Pde C, Lessa PS, Godeiro C Jr, et al. Genetic and environmental findings in early-onset Parkinson's disease Brazilian patients. Mov Disord. 2008;23(9):1228-1233.

35. Latourelle JC, Pankratz N, Dumitriu A, et al. Genomewide association study for onset age in Parkinson disease. BMC Med Genet. 2009; 10:98.
36. Pankratz N, Foroud T. Genetics of Parkinson disease. Genet Med. 2007;9(12):801-811.

37. Keyser RJ, Lesage S, Brice A, Carr J, Bardien S. Assessing the prevalence of PINK1 genetic variants in South African patients diagnosed with early- and late-onset Parkinson's disease. Biochem Biophys Res Commun. 2010;398(1):125-129.

38. Valente EM, Abou-Sleiman PM, Caputo V, et al. Hereditary early-onset Parkinson's disease caused by mutations in PINK1. Science. 2004; 304(5674):1158-1160.

39. Abou-Sleiman PM, Muqit MM, McDonald NQ, et al. A heterozygous effect for PINK1 mutations in Parkinson's disease? Ann Neurol. 2006;60(4):414-419.

40. Nichols WC, Pankratz N, Hernandez D, et al. Genetic screening for a single common LRRK2 mutation in familial Parkinson's disease. Lancet. 2005;365(9457):410-412.

41. Latourelle JC, Sun M, Lew MF, et al. The Gly2019Ser mutation in LRRK2 is not fully penetrant in familial Parkinson's Disease: the GenePD study. BMC Med. 2008;6(1):32.

42. Goldwurm S, Zini M, Mariani L, et al. Evaluation of LRRK2 G2019S penetrance: relevance for genetic counseling in Parkinson disease. Neurology. 2007;68(14):1141-1143.

43. Tong Y, Pisani A, Martella G, et al. R1441C mutation in LRRK2 impairs dopaminergic neurotransmission in mice. Proc Natl Acad Sci U S A. 2009;106(34):14622-14627.

44. Polymeropoulos MH, Lavedan C, Leroy E, et al. Mutation in the alphasynuclein gene identified in families with Parkinson's disease. Science. 1997;276(5321):2045-2047.

45. Lin X, Parisiadou L, Gu XL, et al. Leucine-rich repeat kinase 2 regulates the progression of neuropathology induced by Parkinson's-diseaserelated mutant alpha-synuclein. Neuron. 2009;64(6):807-827.

46. Carballo-Carbajal I, Weber-Endress S, Rovelli G, et al. Leucine-rich repeat kinase 2 induces alpha-synuclein expression via the extracellular signal-regulated kinase pathway. Cell Signal. 2010;22(5):821-827.

47. Nemani VM, Lu W, Berge V, et al. Increased expression of alphasynuclein reduces neurotransmitter release by inhibiting synaptic vesicle reclustering after endocytosis. Neuron. 2010;65(1):66-79.

48. Piccoli G, Condliffe SB, Bauer M, et al. LRRK2 controls synaptic vesicle storage and mobilization within the recycling pool. J Neurosci. 2011;31(6):2225-2237.

49. Siegel GJ, Chauhan NB. Neurotrophic factors in Alzheimer's and Parkinson's disease brain. Brain Res Rev. 2000;33(2-3):199-227.

50. Stoess1 J. Potential therapeutic targets for Parkinson's disease. Expert Opin Ther Targets. 2008;12(4):425-436.

51. Ross OA, Soto-Ortolaza AI, Heckman MG, et al; Genetic Epidemiology Of Parkinson's Disease (GEO-PD) Consortium. Association of LRRK2 exonic variants with susceptibility to Parkinson's disease: a case-control study. Lancet Neurol. 2011;10(10):898-908.

52. Schapira AH. Future directions in the treatment of Parkinson's disease. Mov Disord. 2007;22(17):385-391.

53. Rascol O, Brooks DJ, Korczyn AD, et al. Development of dyskinesias in a 5-year trial of ropinirole and L-dopa. Mov Disord. 2006; 21(11):1844-1850.

54. Holloway RG, Shoulson I, Fahn S, et al. Pramipexole vs levodopa as initial treatment for Parkinson disease a 4-year randomized controlled trial. Arch Neurol. 2004;61(7):1044-1053.

55. Rascol O, Brooks DJ, Korczyn AD, De Deyn PP, Clarke CE, Lang AE. A five-year study of the incidence of dyskinesia in patients with early Parkinson's disease who were treated with ropinirole or levodopa. 056 Study Group. N Engl J Med. 2000;342(20):1484-1491.

56. Oertel WH, Wolters E, Sampaio C, et al. Pergolide versus levodopa monotherapy in early Parkinson's disease patients: The PELMOPET study. Mov Disord. 2006;21(3):343-353.

57. Rinne UK, Bracco F, Chouza C, et al. Early treatment of Parkinson's disease with cabergoline delays the onset of motor complications - results of a double-blind levodopa controlled trial. Drugs. 1998;55(Suppl 1):23-23.

58. Lees AJ, Katzenschlager R, Head J, Ben Shlomo Y. Ten year follow up of three differentinitial treatments in de-novo PD: a randomized trial. Neurology. 2001;57(9):1687-1694. 
59. Hauser RA, Rascol O, Korczyn AD, et al. Ten-year follow-up of Parkinson's disease patients randomized to initial therapy with ropinirole or levodopa. Mov Disord. 2007;22(16):2409-2417.

60. Parkinson Study Group CALM Cohort Investigators. Long-term effect of initiating pramipexole vs levodopa in early Parkinson disease. Arch Neurol. 2009;66(5):563-570.

61. Korczyn AD, Keens J, Oldham M, Macrae S. The safety and efficacy of ropinirole as early therapy in elderly patients with Parkinson's disease. Neurology. 2008;54(7 Suppl 3):A90.

62. Schapira AHV. Neuroprotection and dopamine agonists. Neurology. 2002;58(4 Suppl 1):9-18.

63. Whone AL, Watts RL, Stoessl AJ, et al. Slower progression of Parkinson's disease with ropinirole versus levodopa: the REAL-PET study. Ann Neurol. 2003;54(1):93-101.

64. Ravina B, Marek K, Eberly S, et al. Dopamine transporter imaging is associated with long-term outcomes in Parkinson's disease. Mov Disord. 2012;27(11):1392-1397.

65. Voon V, Hassan K, Zurowski M, et al. Prospective prevalence of pathologic gambling and medication association in Parkinson disease. Neurology. 2006;66(1):1750-1752.

66. Weintraub D, Siderowf AD, Potenza MN, et al. Association of dopamine agonist use with impulse control disorders in Parkinson disease. Arch Neurol. 2006;63(7):969-973.

67. Voon V, Hassan K, Zurowski M, et al. Prevalence of repetitive and reward-seeking behaviors in Parkinson disease. Neurology. 2006;67(7): 1254-1257.

68. Ferreira JJ, Katzenschlager R, Bloem BR, et al. Summary of the recommendations of the EFNS/MDS-ES review on therapeutic management of Parkinson's disease. Eur J Neurol. 2013;20(1): $5-15$.

69. Fox SH, Katzenschlager R, Lim SY, et al. The Movement Disorder Society Evidence-Based Medicine Review Update: treatments for the motor symptoms of Parkinson's disease. Mov Disord. 2011;26(Suppl 3):2-41.

70. Ives NJ, Stowe RL, Marro J, et al. Monoamine oxidase type B inhibitors in early Parkinson's disease: meta-analysis of 17 randomised trials involving 3525 patients. BMJ. 2004;329(7466):593.

71. Stern M; Parkinson Study Group. A controlled trial of rasagiline in Parkinson's disease patients with levodopa-related motor fluctuations (PRESTO Study) [abstract]. Ann Neurol. 2003;54:27.

72. Management of Parkinson's disease: an evidence-based review. Mov Disord. 2002;17:160-166.

73. Thomas A, Iacono D, Luciano AL, Armellino K, Di Iorio A, Onofrj M. Duration of amantadine benefit on dyskinesia of severe Parkinson's disease. J Neurol Neurosurg Psychiatry. 2004;75(1):141-143.

74. Elia AE, Dollenz C, Soliveria P, Albanese A. Motor features and response to oral levodopa in patients with Parkinson's disease under continuous dopaminergic infusion or deep brain stimulation. Eur $J$ Neurol. 2012;19(1):76-83.

75. Pfeiffer RF. Potential of transdermal drug delivery in Parkinson's disease. Drugs Aging. 2002;19:561-570.

76. Ahlskog JE. Beating a dead horse - dopamine and Parkinson disease. Neurology. 2007;69(17):1701-1711.

77. Honig H, Antonini A, Martinez-Martin P, et al. Intrajejunal levodopa infusion in Parkinson's disease: a pilot multicenter study of effects on nonmotor symptoms and quality of life. Mov Disord. 2009;24(10): $1468-1474$.

78. Deuschl G, Schade-Brittinger C, Krack P, et al. A randomized trial of deep-brain stimulation for Parkinson's disease. $N$ Engl J Med. 2006;355(9):896-908.

79. Yu H, Neimat JS. The treatment of movement disorders by deep brain stimulation. Neurotherapeutics. 2008;5(1):26-36.

80. Benabid AL, Pollak P, Gao D, et al. Chronic electrical stimulation of the ventralis intermedius nucleus of the thalamus as a treatment of movement disorders. J Neurosurg. 1996;84(2):203-214.

81. Kleiner-Fisman G, Herzog J, Fisman DN, et al. Subthalamic nucleus deep brain stimulation: summary and meta-analysis of outcomes. Mov Disord. 2006;21(Suppl 14):290-304.
82. Hamani C, Richter E, Schwalb JM, Lozan AM. Bilateral subthalamic nucleus stimulation for Parkinson's disease: a systematic review of the clinical literature. Neurosurgery. 2005;56(6):1313-1321.

83. Schüpbach WM, Maltête D, Houeto JL, et al. Neurosurgery at an earlier stage of Parkinson disease: a randomized, controlled trial. Neurology. 2007;6(4):267-271.

84. Derost PP, Ouchchane L, Morand D, et al. Is DBS-STN appropriate to treat severe Parkinson disease in an elderly population? Neurology. 2007;68(17):1345-1355.

85. Odekerken VJ, van Laar T, Staal MJ, et al. Subthalamic nucleus versus globus pallidus bilateral deep brain stimulation for advanced Parkinson's disease (NSTAPS study): a randomised controlled trial. Lancet Neurol. 2013;12(1):37-44.

86. Okun MS, Foote KD. Subthalamic nucleus vs globus pallidus interna deep brain stimulation, the rematch: will pallidal deep brain stimulation make a triumphant return? Arch Neurol. 2005;62(4):533-536.

87. Anderson VC, Burchiel KJ, Hogarth P, Favre J, Hammerstad JP. Pallidal vs subthalamic nucleus deep brain stimulation in Parkinson disease. Arch Neurol. 2005;62(4):554-560.

88. Schneeberger A, Mandler M, Mattner F, Schmidt W. Vaccination for Parkinson's disease. Parkinsonism Relat Disord. 2012;18(Suppl 1): 11-13.

89. Masliah E, Rockenstein E, Adame A, et al. Effects of alpha-synuclein immunization in a mouse model of Parkinson's disease. Neuron. 2005;16;46(6):857-868.

90. Gross C, Rougier A, Guehl D, Boraud T, Julien J, Bioulac B. High-frequency stimulation of the globus pallidus internalis in Parkinson's disease: a study of seven cases. J Neurosurg. 1997;87(4): 491-498.

91. Pahwa R, Wilkinson S, Smith D, Lyons K, Miyawaki E, Koller WC. High-frequency stimulation of the globus pallidus for the treatment of Parkinson's disease. Neurology. 1997;49(1):249-253.

92. Kumar R, Lang AE, Rodriguez-Oroz MC, et al. Deep brain stimulation of the globus pallidus pars interna in advanced Parkinson's disease. Neurology. 2000;55(12 Suppl 6):34-39.

93. Volkmann J, Allert N, Voges J, Sturm V, Schnitzler A, Freund HJ. Long-term results of bilateral pallidal stimulation in Parkinson's disease. Ann Neurol. 2004;55(6):871-875.

94. Visser-Vandewalle V, van der Linden C, Temel Y, Nieman F, Celik H, Beuls E. Long-term motor effect of unilateral pallidal stimulation in 26 patients with advanced Parkinson disease. J Neurosurg. 2003;99(4):701-707.

95. Calne SM, Kumar A. Young onset Parkinson's disease. Practical management of medical issues. Parkinsonism Relat Disord. 2008;14(2): 133-142.

96. Hoehn MM, Yahr MD. Parkinsonism: onset, progression, and mortality. Neurology. 1967;17(5):427-442.

97. Jankovic J, McDermott M, Carter J, et al. Variable expression of Parkinson's disease: a base-line analysis of the DATATOP cohort. The Parkinson Study Group. Neurology. 1990;40(10):1529-1534.

98. Merola A, Zibetti M, Artusi CA, et al. Subthalamic nucleus deep brain stimulation outcome in young onset Parkinson's disease: a role for age at disease onset? J Neurol Neurosurg Psychiatry. 2012;83(3):251-257.

99. Bronstein JM, DeSalles A, DeLong MR. Stereotactic pallidotomy in the treatment of Parkinson's Disease: an expert opinion. Arch Neurol. 1999;56(9):1064-1069.

100. Marsac L, Chauvet D, Larrat B, et al. MR-guided adaptive focusing of therapeutic ultrasound beams in the human head. Med Phys. 2012;39(2):1141-1149.

101. Hely MA, Fung VSC, Morris JGL. Treatment of Parkinson's Disease. J Clin Neurosci. 2000;7(6):484-494.

102. InSightec. ExAblate Transcranial MR Guided Focused Ultrasound in the Treatment of Essential Tremor. Available from: http://clinicaltrials. gov/ct2/show/NCT01304758. NLM identifier: NCT01304758. Accessed July 10, 2013.

103. Huang Y, Hynynen K. MR-guided focused ultrasound for brain ablation and blood-brain barrier disruption. Methods Mol Biol. 2011;711: 579-593.

104. Jeanmonod D, Werner B, Morel A, et al. Transcranial magnetic resonance imaging-guided focused ultrasound: noninvasive central lateral thalamotomy for chronic neuropathic pain. Neurosurg Focus. 2012;32(1):1. 
105. Evans JR, Barker RA. Neurotrophic factors as a therapeutic target for Parkinson's disease. Expert Opin Ther Targets. 2008;12(4): 437-447.

106. Poewe W, Mahlknecht P, Jankovic J. Emerging therapies for Parkinson's disease. Curr Opin Neurol. 2012;25(4):448-459.

107. Astradsson A, Cooper O, Vinuela A, Isacson O. Recent advances in cell-based therapy for Parkinson disease. Neurosurg Focus. 2008;24(3-4):6.

108. Santos CM. New agents promote neuroprotection in Parkinson's disease models. CNS Neurol Disord Drug Targets. 2012;11(4):410-418.

109. Kirik D, Rosenblad C, Bjorklund A, Mandel RI. Long-term rAAV-mediated gene transfer of GDNF in the rat Parkinson's model: intrastriatal but not intranigral transduction promotes functional regeneration in the lesioned nigrostriatal system. J Neurosci. 2000;20(12): 4686-4700.

110. Gasmi M, Herzog CD, Brandon EP, et al. Striatal delivery of neurturin by CERE-120, an AAV2 vector for the treatment of dopaminergic neuron degeneration in Parkinson's disease. Mol Ther. 2007;15(1): 62-68.

111. Freed CR, Breeze RE, Rosenberg NL, et al. Survival of implanted fetal dopamine cells and neurologic improvement 12 to 46 months after transplantation for Parkinson's disease. N Engl J Med. 1992;327(22): 1549-1555.

112. Piccini P, Brooks DJ, Björklund A, et al. Dopamine release from nigral transplants visualized in vivo in a Parkinson's patient. Nat Neurosci. 1999;2(12):1137-1140.

113. Mendez I, Sanchez-Pernaute R, Cooper O, et al. Cell type analysis of functional fetal dopamine cell suspension transplants in the striatum and substantia nigra of patients with Parkinson's disease. Brain. 2005;128(7):1498-1510.
114. Masliah E, Rockenstein E, Mante M, et al. Passive immunization reduces behavioral and neuropathological deficits in an alpha-synuclein transgenic model of Lewy body disease. PLoS One. 2011;6(4): 193-198.

115. LeWitt PA, Rezai AR, Leehey MA, et al. AAV2-GAD gene therapy for advanced Parkinson's disease: a double-blind, sham-surgery controlled, randomised trial. Lancet Neurol. 2011;10(4):309-139.

116. Marks WJ Jr, Bartus RT, Siffert J, et al. Gene delivery of AAV2neurturin for Parkinson's disease: a double-blind, randomised, controlled trial. Lancet Neurol. 2010;9(12):1164-1172.

117. Linazasoro G. Cell therapy for Parkinson's disease: only young onset patients allowed? Reflections about the results of recent clinical trials with cell therapy and the progression of Parkinson's disease. Cell Transplant. 2006;15:463-473.

118. Farley BG, Koshland GF. Training BIG to move faster: the application of the speed-amplitude relation as a rehabilitation strategy for people with Parkinson's disease. Exp Brain Res. 2005;167(3):462-467.

119. Schenkman M, Donovan J, Tsubota J, Kluss M, Stebbins P, Butler RB. Management of individuals with Parkinson's disease: rationale and case studies. Phys Ther. 1989;69(11):944-955.

120. Sutoo D, Akiyama K. Regulation of brain function by exercise. Neurobiol Dis. 2003;13(1):1-14.

121. Goodwin VA, Richards SH, Taylor RS, Taylor AH, Campbell JL. The effectiveness of exercise interventions for people with Parkinson's disease: a systematic review and meta-analysis. Mov Disord. 208;23(5):631-640.

122. Lewis GN, Byblow WD, Walt SE. Stride length regulation in Parkinson's disease: the use of extrinsic visual cues. Brain. 2000;123(10): 2077-2090.
Degenerative Neurological and Neuromuscular Disease

\section{Publish your work in this journal}

Degenerative Neurological and Neuromuscular Disease is an international, peer-reviewed, open access journal focusing on research into degenerative neurological and neuromuscular disease, identification of therapeutic targets and the optimal use of preventative and integrated treatment interventions to achieve improved outcomes, enhanced

\section{Dovepress}

survival and quality of life for the patient. The manuscript management system is completely online and includes a very quick and fair peer-review system. Visit http://www.dovepress.com/testimonials.php to read real quotes from published authors. 